\title{
Die Frauenrechts-Convention in der Mozart - Halle.
}

Gestern, den 13. Mai, fand in der Mozart - Halle eine Versammlung von Männem und Frauen statt, welche die ewigen Rechte der Menschheit auch auf die Frauen ausgedehnt zu sehen wünschen. Trotz des erhobenen Eintrittsgeldes war der Saal wohl angefüllt. Frau Cäsar ${ }^{107}$ Anthony wurde zur Präsidentin ernannt. Sie las eine kurze Geschichte der Frauenbewegung, von Elisabeth Stanton ${ }^{108}$ verfaßt, vor. Herr Stephan Andrews bestieg alsdann die Rednerbühne und sprach:

„Die Revolution, welche die Frau als „freies Wesen“ erklärte, ging vielleicht weiter, als Viele beabsichtigten. Er widme der Frauenrechtsbewegung das größte Mitgefühl, aber sehe sie nur als eine Stufe zu Größerem an. Er glaube, daß der Frau erstes Recht sei, den Vater ihres Kindes zu wählen. Er wünschte zu wissen, ob eine Discussion dieser wirklichen Freiheit der Frauen hier willkommen sei? wenn nicht, so möge man es ihm sagen."

Die Präsidentin entgegnete: bei einer freien Platform sei jede Discussion willkommen und keine Gefahr zu befürchten, da die Wahrheit herrschen müsse.

Hr. Philipp Moore von New-York wünschte, die Seinen möchten zeigen, daß sie menschliche Wesen seien. Kirche und Staat schienen noch daran zu zweifeln. Emestine Rose besprach die geistige Gleichheit beider Geschlechter und bemerkte: Manche fragen, was kann die Frau denn thun? sie wolle fragen: was kann sie $\mathbf{n} \mathbf{i} \mathbf{~ h ~ t ~}$ thun?

Lucy Stone tadelte die „Tribune“, den „Liberator" und den „N.Y. Independent“, daß sie die Frauen in Kansas, welche so muthig und wacker dort für die Freiheit der schwarzen Menschen kämpften, vergäßen!

Nachdem noch viele andere Frauen und Männer gesprochen hatten, so Wendell Philipp's, Lucy Colman und der Quäker Moore, welcher den Frauen anrieth, „Sharp rifles" zu ergreifen und ihr Recht sich zu holen, wurden die Beschlüsse verlesen; die bedeutendsten davon sind: Es solle ein Comite durch die Präsidentin niedergesetzt werden, welches womöglich einen Vertreter von jedem Staate und Territorium habe. Bei den verschiedenen Gesetzgebungen sollen dann Eingaben überreicht und ein Gehör verlangt werden in dieser hochwichtigen Frage.

107 Gemeint ist: Susan B. Anthony (1820 - 1906).

108 Elisabeth Cady Stanton, 1815 - 1902. 